\title{
Prognostic Role of High Stathmin 1 Expression in Patients with Solid Tumors: Evidence from a Meta-Analysis
}

\author{
Qingyan Mao Zhen Chen Kun Wang Renfang Xu Hao Lu Xiaozhou He \\ Department of Urology, The Third Affiliated Hospital of Soochow University, Changzhou, China
}

\section{Key Words}

Stathmin $1 \cdot$ Prognosis $\bullet$ Solid tumor $・$ Biomarker $・$ Meta-analysis

\begin{abstract}
Background/Aims: Several recent studies have demonstrated that Stathmin 1expression may be closely associated with prognosis in patients with various types of cancers. In the present study, we conducted a meta-analysis of all available studies in the English literature to assess the prognostic value of Stathmin 1expression in patients with solid cancers. Methods: The online databases PubMed, Embase, and Web of Science were searched for literature regarding Stathmin 1 and its association with patient outcomes associated with solid cancers. Results: A total of 23 articles including 26 studies that contained 5335 patients were retrieved and analyzed. Our results indicated that high Stathmin 1 expression yielded a worse overall survival (OS) (hazard ratio $[\mathrm{HR}]=2.17,95 \%$ confidence interval $[\mathrm{CI}]: 1.81-2.60$ ), disease-free survival (DFS) (HR = 2.46, 95\% CI: 2.00-3.02), disease-specific survival (DSS) (HR $=1.98,95 \%$ CI: $1.58-$ 2.47) and progression-free survival (PFS)/recurrence-free survival (RFS) (HR $=2.09,95 \% \mathrm{CI}$ : 1.51-2.89). Furthermore, the association of high Stathmin 1 expression with poor survival was significant even for sub-group analyses of different tumor types, ethnicities, methods used to calculate HRs, detected methods, and analysis types. Conclusion: In summary, this metaanalysis determined that high Stathmin 1 expression is associated with poor prognosis in patients with solid cancers and expression of this protein could be a clinically useful prognostic biomarker.

\section{Introduction}

Based on GLOBOCAN estimates, approximately 14.1 million new cancer cases and 8.2 million cancer-related deaths were reported in 2012 worldwide. The occurrence of cancer is increasing due to population growth and aging, as well as an increasing prevalence of established risk factors such as smoking, obesity, physicalinactivity, and changing reproductive patterns associated with urbanization and economic development [1]. Prevention and early detection should be the mainstays of cancer control. Population screenings of asymptomatic 


\section{Cellular Physiology Cell Physiol Biochem 2018;50:66-78 and Biochemistry Published online: 3 October $2018 \begin{aligned} & \text { DOI: 10.1159/000493958 } 2018 \text { The Author(s). Published by S. Karger AG, Basel } \\ & \text { www.karger.com/cpb }\end{aligned}$ \\ Mao et al.: High Stathmin 1 Expression in Solid Tumors}

individuals allows early detection when a cancer is localized and potentially curable, or the detection of precancerous lesions, which can be prevented from developing into invasive cancer [2]. Besides an early diagnosis, optimal therapeutic strategies that are based on the prediction of patient outcome also contribute to the successful management of cancer. Therefore, novel cancer biomarkers with improved sensitivity and specificity are essential for this fatal disease. Recently, the Stathmin 1 has emerged as a potential marker for cancer prognostication.

Stathmin 1, also known as oncoprotein 18 (0p18), p17, p18, p19, 19K, LAP 18, and metablastin, is a ubiquitous, highly conserved 18 -kDa cytosolic phosphoprotein [3]. It is encoded by the human STMN1 gene, which is located at chromosome 1p35-36.1 [4]. Stathmin 1 is composed of 149 amino acids organized into four domains (I-IV) as defined by limited proteolysis. The core region (amino acids 42-126) is the minimum fragment required for tubulin interaction with the additional requirement of either an $\mathrm{N}$ - or C-terminal extension. There are four phosphorylation domains, designated as Ser 16, 25, 38, and 63. Of the four phosphorylation sites, only Ser 16 is conserved throughout the Stathmin 1 family [5, 6]. As a major microtubule-destabilizing protein, it interacts directly with soluble tubulin to form a complex that sequesters free tubulin and impedes the polymerization of microtubules, which increases the upregulation of microtubule dynamics [7, 8]. It is involved in various cell functions such as cell cycle regulation, promoting cell proliferation, mobility, metastasis, and resistance to antimicrotubule therapy [7, 9]. Recently, numerous studies have demonstrated that Stathmin 1 is overexpressed in a variety of cancers, including urinary bladder, oral, ovarian, lung, nasopharyngeal, liver, esophageal, colorectal, and breast cancer; it has a positive correlation with nodal involvement, distant metastasis, clinical stage, and a poor prognosis [10-18]. Nevertheless, the reliability and prognostication of Stathmin 1 in solid tumors have not yet been methodically analyzed. Therefore, we conducted a meta-analysis to explore the relationship between Stathmin 1 expression and the prognosis of solid cancers. We hypothesized that high Stathmin 1 expression represents a biomarker of poor survival in patients with solid tumors.

\section{Materials and Methods}

\section{Search strategy}

This meta-analysis was conducted in accordance with the Preferred Reporting Items for Systematic Reviews and Meta-Analyses (PRISMA) guidelines [19]. A systematic search of PubMed, Embase, and Web of Science, for articles published in the English language, was performed by using the following search terms: "stathmin 1 or STMN1 or oncoprotein 18 or Op18 or p17 or p18 or p19 or 19K or LAP 18 or metablastin" (all fields), "cancer or carcinoma or tumor or neoplasm" (all fields), and "prognosis or prognostic or survival or outcome" (all fields). In addition, we also checked the references of all identified studies in order to retrieve unpublished but relevant studies.

\section{Selection criteria}

The inclusion criteria to select relevant published studies were as follows: (1) clinical study examining the association of high Stathmin 1 expression and cancer prognostic value; (2) studies that directly reported hazard ratios (HRs) and 95\% confidence intervals (CIs), or allowed for their calculation; (3) patient prognostic outcomes, including overall survival (OS), disease-free survival (DFS), disease-specific survival (DSS), progression-free survival (PFS), and recurrence-free survival (RFS); and, (4) retrospective or prospective study design. Our exclusion criteria were: (1) publications related to meeting records, letters, review papers, comments, case reports, or clinical guidelines; (2) articles concerning cell lines or animal studies; (3) studies with sample sizes smaller than 40; and, (4) in case duplicate studies were retrieved, all but the study with the largest sample size were excluded. 


\section{Cellular Physiology Cell Physiol Biochem 2018;50:66-78

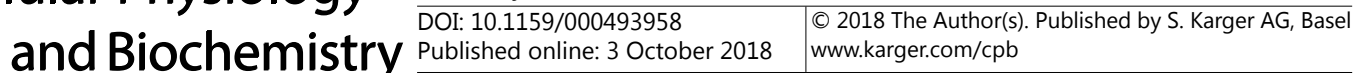 \\ Mao et al.: High Stathmin 1 Expression in Solid Tumors}

Quality assessment

The eligible studies included in our meta-analysis were independently assessed by two researchers according to the Newcastle-Ottawa Scale (NOS) guidelines on a rating scale from 0 (lowest) to 9 (highest) [20]. Studies with scores of 6 or more were rated as being of high quality.

\section{Data extraction and conversion}

Relevant characteristics and outcome data were extracted from the literature by two independent reviewers. The main data of articles were tabulated as follows: (1) basic characteristics: first author's last name, publication year, country, and ethnicity; (2) clinical data: tumor type, gender, case number, age, treatment, tumor stage, follow-up duration, and detected method; (3) cut-off value and high expression number; and (4) HRs for OS, DFS, DSS, PFS, RFS, as well as their 95\% CIs. In cases wherein the study provided the results of univariate and multivariate analyses, we chose the latter. Any disagreement was resolved by discussion among the investigators.

Most of the eligible studies included data pertaining to HRs and 95\% CIs. If the HR and 95\% CI were not available, we calculated the values by using the original data provided in the paper. If only KaplanMeier curves of Stathmin 1 were available, we were able to reconstruct the HRs and $95 \%$ CIs from the data extracted from the survival plots. All the calculation methods mentioned above were previously reported by Parmar et al. [21] and Tierney et al. [22]. We also communicated with the corresponding authors of the published studies by email to request any additional data that were required for the meta-analysis.

\section{Statistical analysis}

High or positive expression of Stathmin 1 was defined according to the cut-off values provided in the analyzed articles. Pooled HRs and 95\% CIs were used to analyze the association between Stathmin 1 expression and the survival of patients with solid tumors. An observed $H R>1$ implied a poorer prognosis in patients with high Stathmin 1 expression, while $\mathrm{HR}<1$ indicated a better prognosis. We used Cochran's $Q$ test and Higgins I-squared statistic $\left(\mathrm{I}^{2}\right)$ for measuring the heterogeneity of the combined HRs. If the P value was less than 0.05 and/or $\mathrm{I}^{2}$ was larger than $50 \%$, the heterogeneity of the combined HRs was considered statistically significant. A random-effects model (DerSimonian-Laird method) was used. In the absence of heterogeneity among the studies, a fixed-effects model (the Mantel-Haenszel method) was applied. The factors that may have led to heterogeneity were further analyzed by subgroup analysis. Publication bias was assessed using Begg's and Egger's tests. All data analyses were performed with STATA version 12.0 (Stata Corporation, College Station, TX, USA). A P value lower than 0.05 was considered statistically significant on two-sided tests.

\section{Results}

\section{Search results}

The process of searching and filtering the literature is shown in Fig. 1. A total of 698 records were retrieved in accordance with our search method. Following the screening of the titles, abstracts, publication categories, and full text of each article, only 42 articles qualified for the present analysis. Among these, 19 articles were excluded (9 lacked important data, 4 used continuous or two cut-offs for Stathmin 1 expression, and 6 reported only odds ratios or relative risk estimates). Finally, 23 articles including 26 studies, (because 3 articles included two independent cohort studies, respectively) which involved 5335 patients, were included in the final meta-analysis [10-18, 22-36].

\section{Study characteristics}

The characteristics of the studies are presented in Table 1 . The 23 included articles were published between 2004 and 2017, and included patients from Sweden, Japan, China, Germany, Taiwan, Norway, Slovenia, and the USA. The category of cancers included oral squamous cell carcinoma(OSCC) (3 studies, 320 patients), ovarian cancer (2 studies, 398 patients), meningioma (2 studies, 191 patients), esophageal squamous cell carcinoma (ESCC) (3 studies, 436 patients), endometrial cancer (3 studies, 1433 patients), breast cancer (4 
studies, 1214 patients), urinary bladder cancer (2 studies, 581 patients), non-small cell lung cancer (NSCLC) (1 study, 113 patients), nasopharyngeal carcinoma (NPC) (1 study, 98 patients), medulloblastoma (1 study, 180 patients), hepatocellular carcinoma (HCC) (1 study, 58 patients),gastric adenocarcinoma (1 study, 180 patients), colorectal cancer (CRC) (1 study, 149 patients), and colon cancer (1 study, 105 patients). The ethnicity of the patients was either Asian $(35.3 \%, 1881)$ or Caucasian (64.7\%, 3454). HRs were reported directly in 22 studies and estimated indirectlyin the other 4 studies. The Stathmin 1 protein expression was assessed by immunohistochemistry

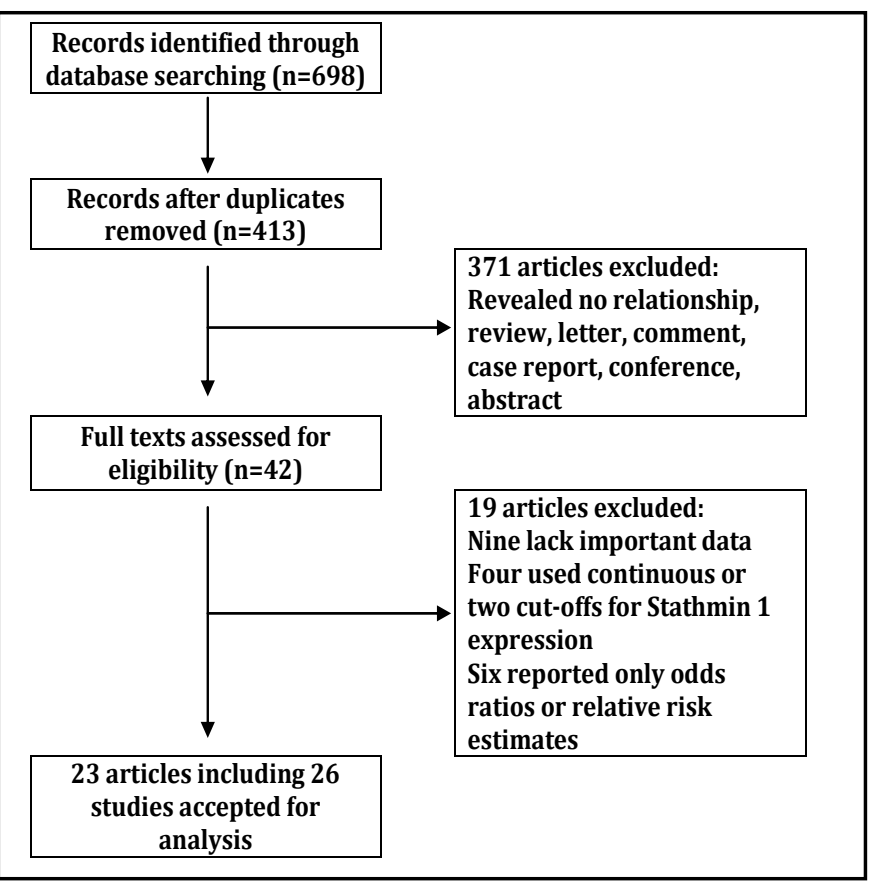

Fig. 1. Flow diagram of the patient selection process for this study. (IHC) in 20 studies and by western blotting in 1 study, with the other 5 reports using quantitative real-time polymerase chain reaction (qRT-PCR) to detect STMN1mRNA level. There were 18 studies that used multivariate analysis for statistical tests and 3 studies utilized univariate analysis, while the other 5 studies did not report a statistical technique. The cut-off values used in each study varied.

\section{Quality assessment}

According to the Newcastle-Ottawa scale, we assessed the quality of the 26 eligible studies included in our meta-analysis. The quality scores of the studies varied from 4 to 9 , with a mean score of 6 . A higher score was indicative of a better methodology. All 26 studies were included in the subsequent analysis.

\section{Meta-analysis of OS}

The main results of this meta-analysis are shown in Table 2. Fourteen studies, which included 1855 patients, were analyzed in the current meta-analysis to assess the prognostic value of highly-expressed Stathmin 1 in solid tumors. As the studies evaluating OS were not of obvious statistical heterogeneity $\left(\mathrm{I}^{2}=18.7 \%, \mathrm{P}=0.249\right)$, we used a fixed-effects model to pool the HRs. As shown in Fig. 2A, the pooled analysis demonstrated that high Stathmin 1 expression was significantly associated with unfavorable OS (HR $=2.17,95 \% \mathrm{CI}: 1.81-2.60$, $\mathrm{P}<0.001)$.

In the tumor type subgroup, as only one study analyzed OS for meningioma, endometrial cancer, breast cancer, NPC, medulloblastoma, CRC, and colon cancer, respectively, we combined them with the analysis of other cancers. High Stathmin 1 expression was associated with poorer OS for OSCC (HR $=2.47,95 \% \mathrm{CI}: 1.29-4.75, \mathrm{P}=0.007)$, ovarian cancer ( $\mathrm{HR}=3.12,95 \% \mathrm{CI}: 1.84-5.28, \mathrm{P}<0.001)$, ESCC (HR $=2.36,95 \% \mathrm{CI}: 1.51-3.67, \mathrm{P}<0.001)$, and other cancers (HR $=1.96,95 \%$ CI: 1.56-2.46, $\mathrm{P}<0.001$ ) (Fig. 3A). Meanwhile, Stathmin 1 expression was significantly associated with worse OS in Caucasian patients (HR $=1.83$, 95\% CI: 1.42-2.35, $\mathrm{P}<0.001$ ) and Asian patients (HR $=2.61$; 95\% CI: 2.01-3.39; $\mathrm{P}<0.001$ ). High Stathmin 1 expression remained significantly associated with poor OS on subgroup analysis as well: HRs reported directly in text ( $\mathrm{HR}=2.10,95 \% \mathrm{CI}: 1.73-2.54, \mathrm{P}<0.001)$, HRs 


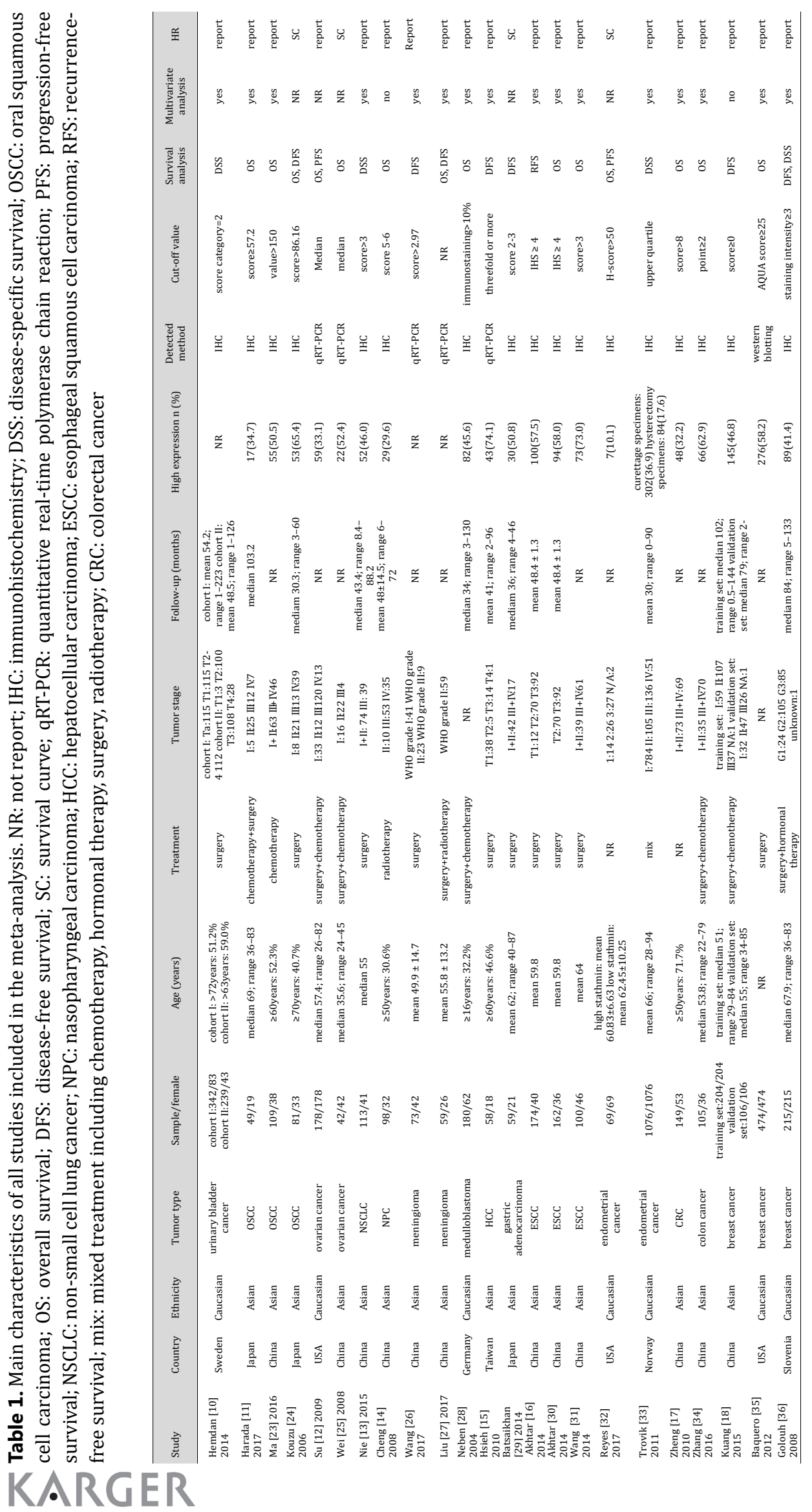




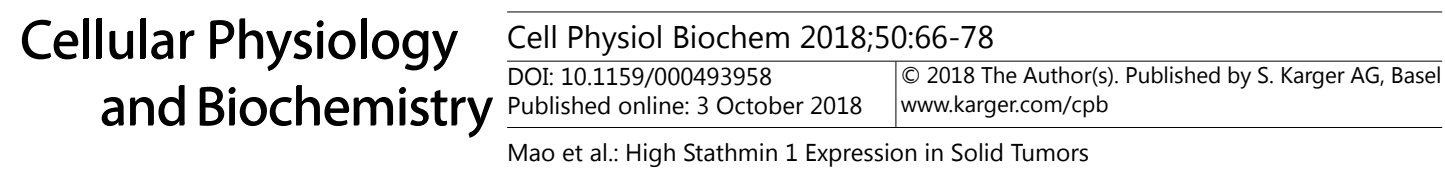

Table 2. Pooled hazard ratios for OS according to subgroup analyses. OS: overall survival; HR: hazard ratio; CI: confidence intervals; OSCC: oral squamous cell carcinoma; ESCC: esophageal squamous cell carcinoma; IHC: immunohistochemistry; qRT-PCR: quantitative real-time polymerase chain reaction; NR: not report. * indicates that the difference was statistically significant

\begin{tabular}{|c|c|c|c|c|c|c|c|c|}
\hline \multirow{2}{*}{ Variables } & \multirow{2}{*}{ Studies } & \multirow{2}{*}{ Patients } & \multirow{2}{*}{\multicolumn{2}{|c|}{$\mathrm{HR}(95 \% \mathrm{CI})$}} & \multirow{2}{*}{$P$ value } & \multirow{2}{*}{ Model } & \multicolumn{2}{|c|}{ Heterogeneity } \\
\hline & & & & & & & $I^{2}$ & $\mathrm{P}$ \\
\hline \multirow{2}{*}{\multicolumn{9}{|c|}{ Tumor type }} \\
\hline & & & & & & & & \\
\hline oscC & 3 & 239 & 2.47 & $1.29,4.75)$ & $0.007 *$ & fixed & $23.0 \%$ & 0.273 \\
\hline Ovarian cancer & 2 & 220 & 3.12 & $1.84,5.28)$ & $<0.001 *$ & fixed & $0.0 \%$ & 0.404 \\
\hline ESCC & 2 & 262 & 2.36 & $1.51,3.67)$ & $<0.001^{*}$ & fixed & $0.0 \%$ & 0.808 \\
\hline Other cancers & 7 & 1134 & 1.96 & $1.56,2.46)$ & $<0.001^{*}$ & fixed & $38.5 \%$ & 0.135 \\
\hline \multicolumn{9}{|l|}{ Ethnicity } \\
\hline Caucasian & 4 & 901 & 1.83 & $1.42,2.35)$ & $<0.001^{*}$ & fixed & $45.6 \%$ & 0.138 \\
\hline Asian & 10 & 954 & 2.61( & $2.01,3.39)$ & $<0.001 *$ & fixed & $0.0 \%$ & 0.655 \\
\hline \multicolumn{9}{|l|}{ HR obtain method } \\
\hline Reported in text & 11 & 1663 & 2.100 & $1.73,2.54)$ & $<0.001 *$ & fixed & $17.8 \%$ & 0.275 \\
\hline Data extrapolated & 3 & 192 & 2.97 & $1.67,5.31)$ & $<0.001^{*}$ & fixed & $22.5 \%$ & 0.275 \\
\hline \multicolumn{9}{|l|}{ Detected method } \\
\hline IHC & 10 & 1102 & 2.26 & $1.78,2.88)$ & $<0.001 *$ & fixed & $8.5 \%$ & 0.364 \\
\hline qRT-PCR & 3 & 279 & 2.97 & $(.95,4.52)$ & $<0.001^{*}$ & fixed & $0.0 \%$ & 0.676 \\
\hline western blotting & 1 & 474 & 1.57 & $(.09,2.25)$ & $0.015^{*}$ & - & - & - \\
\hline \multicolumn{9}{|l|}{ Analysis type } \\
\hline Multivariate & 9 & 1387 & 1.95 & $(.59,2.40)$ & $<0.001^{*}$ & fixed & $0.0 \%$ & 0.509 \\
\hline Univariate & 1 & 98 & 5.88 & $.38,20.00)$ & $<0.001^{*}$ & - & - & - \\
\hline NR & 4 & 370 & 2.87 & $1.90,4.35)$ & $<0.001^{*}$ & fixed & $0.0 \%$ & 0.456 \\
\hline \\
\hline \multicolumn{2}{|l|}{$\begin{array}{l}\text { sudy } \\
\text { 10 }\end{array}$} & нR (95\% Сा) & weght & & & & \multirow{3}{*}{ HR ( $95 \%$ Cl) } & \multirow{3}{*}{$\begin{array}{l}\% \\
\text { Weight }\end{array}$} \\
\hline \multirow{11}{*}{ 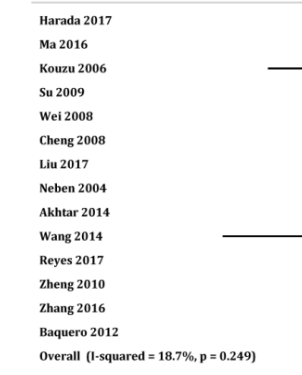 } & \multirow{2}{*}{+} & $-8.8990 .99,79970)$ & 0.68 & $\begin{array}{l}\text { Study } \\
\text { ID }\end{array}$ & & & & \\
\hline & & 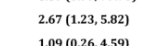 & 543 & & & & & \\
\hline & + & 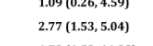 & $\begin{array}{c}160 \\
926\end{array}$ & Kouzu 2006 & & \multirow{3}{*}{+} & \multirow{9}{*}{\multicolumn{2}{|c|}{$\begin{aligned} 1.67(0.74,3.78) & 6.31 \\
4.12(1.65,7.98) & 6.73 \\
2.38(1.85,3.27) & 52.18 \\
3.92(1.53,10.06) & 4.72 \\
-7.20(0.74,70.10) & 0.81 \\
1.83(1.11,3.32) & 11.78 \\
2.79(1.16,6.66) & 5.52 \\
2.55(1.41,4.61) & 11.95 \\
2.46(2.00,3.02) & 100.00\end{aligned}$}} \\
\hline & 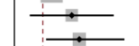 & 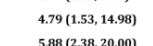 & 2.53 & Wang 2017 & & & & \\
\hline & \multirow{7}{*}{$\begin{array}{l}\frac{\square}{\square} \\
\qquad \frac{\square}{\square} \\
\frac{i}{\square} \\
\frac{\square}{\square}\end{array}$} & $\begin{array}{l}5.888(238,20.000) \\
2.73(156,625)\end{array}$ & 2.91 & Liu 2017 & & & & \\
\hline & & 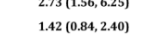 & $\begin{array}{l}6.83 \\
11.94\end{array}$ & Hsieh 2010 & & $\div$ & & \\
\hline & & 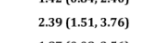 & 15.86 & Batsaikhan 2014 & & \begin{tabular}{|c|ccc} 
\\
\end{tabular} & & \\
\hline & & 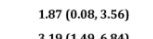 & 0.89 & Kuang 2015 traini & & + & & \\
\hline & & $\begin{array}{l}3.19(149,6.847) \\
1.93(125,6,32)\end{array}$ & $\begin{array}{l}5.67 \\
501\end{array}$ & Kuang 2015 valida & ion set & $\div$ & & \\
\hline & & 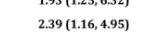 & 6.21 & Golouh 2008 & & + & & \\
\hline & & $\begin{array}{l}1.57(109,2.25) \\
2.17(718.2 .60)\end{array}$ & $\begin{array}{l}25.17 \\
1000.00 \\
\end{array}$ & Overall (1-squared & $=0.0 \%, p=0.612)$ & $\bar{\Delta}$ & & \\
\hline .0125 & & 79.7 & & & 1143 & & 70.1 & \\
\hline $\mathrm{c}_{\text {Study }}$ & & & $\%$ & $\mathrm{D}$ & & & & \\
\hline ID & & HR $95 \%$ Cl) & Weight & Study & & & & $\%$ \\
\hline & & & & & & & & Weiot \\
\hline Hemdan 2014 cohortl & $\longrightarrow$ & $2.04(1.13,3$. & 68) 14.27 & ID & & & HR $(95 \%$ CI) & Weight \\
\hline Hemdan 2014 cohortII & $\rightarrow$ & $\begin{array}{l}1.76(1.04,2 . \\
2.25\end{array}$ & 99) 17.83 & & & & & \\
\hline Nie 2015 & & $2.25(1.32,3$. & 83) 17.57 & Su 2009 & & - & $-2.43(1.41,4.19)$ & 1) 35.66 \\
\hline Trovik 2011 curettage specimens & $\rightarrow$ & $1.68(1.05,2$. & 67) 22.83 & Reyes 2017 & & & $1.87(0.89,3.93)$ & 3) 19.18 \\
\hline $\begin{array}{l}\text { Trovik } 2011 \text { hysterectomy specimens } \\
\text { Golouh } 2008\end{array}$ & $\rightarrow$ & $\begin{array}{r}1.68(1.13,3 . \\
-3.47(1.75,6.4\end{array}$ & 85) 16.84 & Akhtar 2014 & & & $1.94(1.19,3.14)$ & 45.16 \\
\hline Overall (1-squared $=0.0 \%, \mathrm{p}=0.573$ ) & $\diamond$ & $1.98(1.58,2$. & 47) 100.00 & overall (I-square & $=0.0 \%, p=0.788)$ & & $2.09(1.51,2.89)$ & 100.00 \\
\hline .146 & 1 & 6.86 & & .23 & & & 4.19 & \\
\hline
\end{tabular}

Fig. 2. Forest plots of studies evaluating the hazard ratios of high Stathmin 1 expression in solid cancers for (A) OS, (B) DFS, (C) DSS, and (D) PFS/RFS.

\section{KARGER}




\section{Cellular Physiology Cell Physiol Biochem 2018;50:66-78 and Biochemistry Published online: 3 October 2018 \begin{tabular}{l|l} 
DOI: 10.1159/000493958 & $\begin{array}{l}\text { C } 2018 \text { The Author(s). Published by S. Karger AG, Basel } \\
\text { www.karger.com/cpb }\end{array}$
\end{tabular} \\ Mao et al.: High Stathmin 1 Expression in Solid Tumors}

estimated indirectly by data extrapolated (HR $=2.97,95 \%$ CI: $1.67-5.31, \mathrm{P}<0.001)$; IHC for Stathmin 1 protein (HR $=2.26,95 \%$ CI: $1.78-2.88, \mathrm{P}<0.001$ ), qRT-PCR for STMN1mRNA (HR $=2.97,95 \%$ CI: $1.95-4.52, \mathrm{P}<0.001)$; multivariate analysis $(\mathrm{HR}=1.95,95 \% \mathrm{CI}: 1.59-2.40, \mathrm{P}$ $<0.001)$, and analysis type not reported ( $\mathrm{HR}=2.87,95 \% \mathrm{CI}: 1.90-4.35, \mathrm{P}<0.001)$.

\section{Meta-analysis of DFS}

Eight studies that included 855 patients provided suitable data for DFS analysis. The main results are listed in Table 3. In the absence of heterogeneity among the studies $\left(\mathrm{I}^{2}=\right.$ $0.0 \%, \mathrm{P}=0.612$ ), we also used a fixed-effects model to pool the HRs. The pooled analysis demonstrated that high Stathmin 1 expression was significantly associated with worse DFS (HR $=2.46,95 \%$ CI: 2.00-3.02, $\mathrm{P}<0.001$ ) (Fig. 2B). The negative effect of high Stathmin 1 expression on DFS was verified in the tumor type subgroup with breast cancer (HR = 2.27, 95\% CI: $1.55-3.31, \mathrm{P}<0.001$ ), meningioma (HR $=2.53,95 \% \mathrm{CI}: 1.94-3.31, \mathrm{P}<0.001$ ), and other cancers (including OSCC, HCC, and gastric adenocarcinoma) (HR $=2.59,95 \% \mathrm{CI}$ : 1.43-4.70, $\mathrm{P}=0.002$ ) (Fig. 3B). In addition, differences were significant in other subgroup analyses: Asian patients (HR $=2.45 ; 95 \% \mathrm{CI}$ : 1.97-3.04; $\mathrm{P}<0.001$ ); HRs reported directly in article text (HR $=2.50,95 \%$ CI: 2.02-3.09, $\mathrm{P}<0.001)$; IHC for Stathmin 1 protein $(\mathrm{HR}=2.21$, 95\% CI: 1.57-3.10, P <0.001), qRT-PCR for STMN1 mRNA (HR $=2.61,95 \%$ CI: 2.02-3.38, $\mathrm{P}<0.001)$; multivariate analysis ( $\mathrm{HR}=2.60,95 \% \mathrm{CI}: 2.06-3.30, \mathrm{P}<0.001)$, and univariate analysis (HR $=2.09,95 \% \mathrm{CI}: 1.28-3.42, \mathrm{P}=0.003)$. However, subgroup analysis did not show a significant difference in HRs estimated indirectly by data extrapolated ( $\mathrm{HR}=1.97,95 \% \mathrm{CI}$ : $0.92-4.25, \mathrm{P}=0.083$ ) or analysis type not reported ( $\mathrm{HR}=1.97,95 \% \mathrm{CI}: 0.92-4.25, \mathrm{P}=0.083$ ).

\section{Meta-analysis of DSS}

Six studies that included 2204 patients were included in this part of the meta-analysis. High Stathmin 1 expression yielded a worse DSS $\left(\mathrm{I}^{2}=0.0 \%, \mathrm{P}=0.573\right.$, fixed-effects model; $\mathrm{HR}=1.98,95 \%$ CI: 1.58-2.47, $\mathrm{P}<0.001$ ) (Fig. 2C). In addition, Stathmin 1 was significantly associated with worse DSS in endometrial cancer ( $\mathrm{HR}=1.68,95 \% \mathrm{CI}: 1.18-2.39, \mathrm{P}=0.004)$, urinary bladder cancer ( $\mathrm{HR}=1.88,95 \% \mathrm{CI}: 1.27-2.79, \mathrm{P}=0.002)$, and other cancers (included

Table 3. Pooled hazard ratios for DFS according to subgroup analyses. DFS: disease-free survival; HR: hazard ratio; CI: confidence intervals; IHC: immunohistochemistry; qRT-PCR: quantitative real-time polymerase chain reaction; NR: not report. * indicates that the difference was statistically significant

\begin{tabular}{lccccccc}
\hline Variables & Studies & Patients & HR $(95 \% \mathrm{CI})$ & P value & Model & \multicolumn{2}{c}{ Heterogeneity } \\
$\mathrm{I}^{2}$ & $\mathrm{P}$ \\
\hline $\begin{array}{l}\text { All } \\
\text { Tumor type }\end{array}$ & 8 & 855 & $2.46(2.00,3.02)$ & $<0.001^{*}$ & fixed & $0.0 \%$ & 0.612 \\
$\begin{array}{l}\text { Breast cancer } \\
\text { Meningioma }\end{array}$ & 3 & 525 & $2.27(1.55,3.31)$ & $<0.001^{*}$ & fixed & $0.0 \%$ & 0.649 \\
$\begin{array}{l}\text { Other cancers } \\
\text { Ethnicity }\end{array}$ & 2 & 132 & $2.53(1.94,3.31)$ & $<0.001^{*}$ & fixed & $39.4 \%$ & 0.199 \\
Caucasian & 3 & 198 & $2.59(1.43,4.70)$ & $0.002^{*}$ & fixed & $23.9 \%$ & 0.269 \\
Asian & 1 & 215 & $2.55(1.41,4.61)$ & $0.002^{*}$ & - & - & - \\
HR obtain method & 7 & 640 & $2.45(1.97,3.04)$ & $<0.001^{*}$ & fixed & $0.0 \%$ & 0.496 \\
$\begin{array}{l}\text { Reported in text } \\
\text { Data extrapolated }\end{array}$ & 6 & 715 & $2.50(2.02,3.09)$ & $<0.001^{*}$ & fixed & $0.0 \%$ & 0.601 \\
$\begin{array}{l}\text { Detected method } \\
\text { IHC }\end{array}$ & 2 & 140 & $1.97(0.92,4.25)$ & 0.083 & fixed & $28.8 \%$ & 0.236 \\
qRT-PCR & 5 & 665 & $2.21(1.57,3.10)$ & $<0.001^{*}$ & fixed & $0.0 \%$ & 0.668 \\
Analysis type & 3 & 190 & $2.61(2.02,3.38)$ & $<0.001^{*}$ & fixed & $17.2 \%$ & 0.299 \\
Multivariate & & & & & & & \\
Univariate & 2 & 405 & $2.60(2.06,3.30)$ & $<0.001^{*}$ & fixed & $0.0 \%$ & 0.49 \\
NR & 2 & 310 & $2.09(1.28,3.42)$ & $0.003^{*}$ & fixed & $0.0 \%$ & 0.435 \\
\hline
\end{tabular}




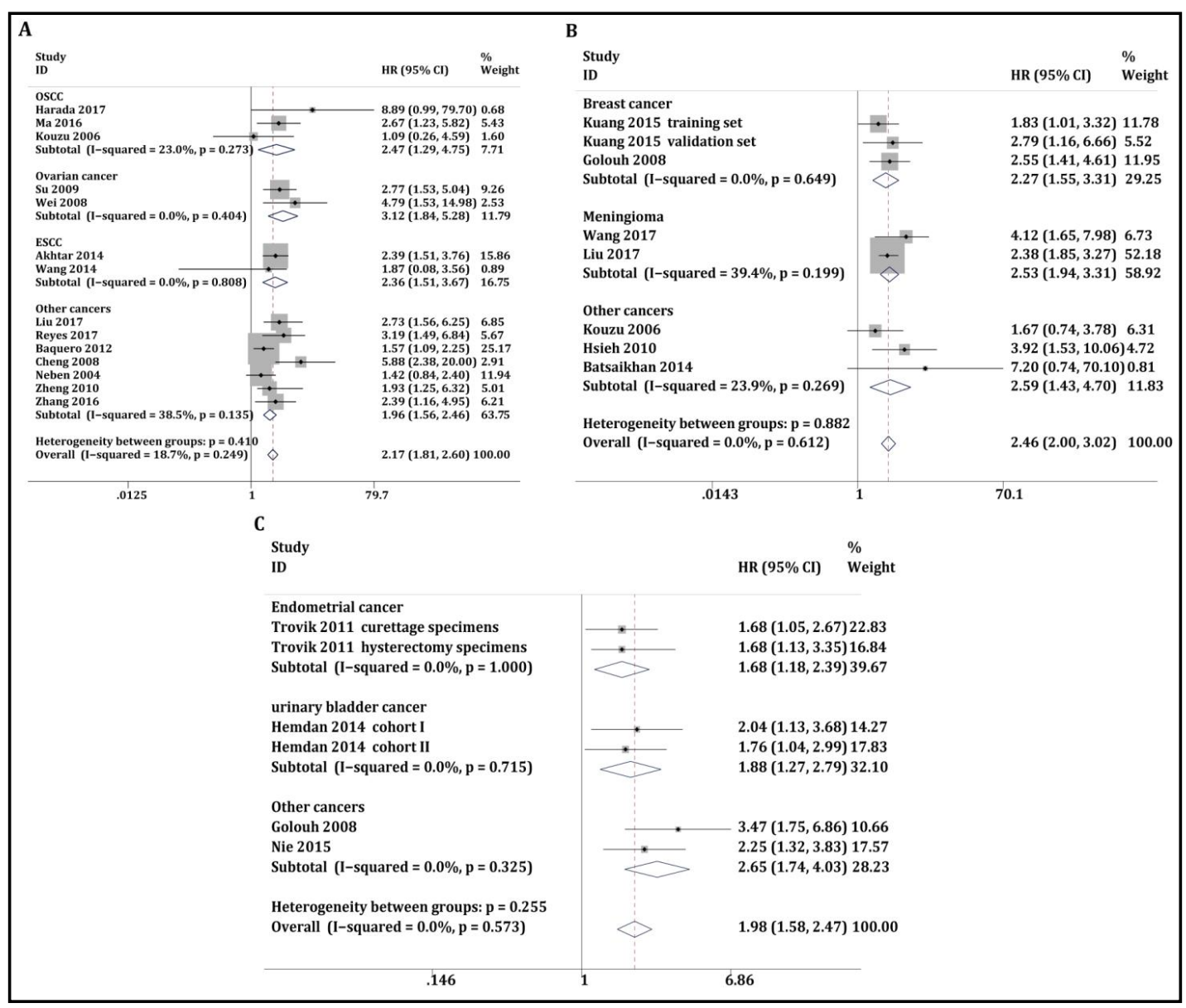

Fig. 3. Forest plot of the relationship between high Stathmin 1 expression and (A) OS, (B) DFS, and (C) DSS, in patients with various types of cancers.

breast cancer and NSCLC) (HR = 2.65, 95\% CI: 1.74-4.03, P < 0.001) (Fig. 3C), and other subgroup analyses.

\section{Meta-analysis of PFS/RFS}

Considering the similarities between RFS and PFS, we merged them together to conduct this analysis. Three studies that included 421 patients revealed a significant positive association between high Stathmin 1 expression and poor PFS $/$ RFS $\left(\mathrm{I}^{2}=0.0 \%, \mathrm{P}=0.778\right.$, fixed-effects model; HR = 2.09, 95\% CI: 1.51-2.89, P < 0.001) (Fig. 2D). Likewise, a similar result was found in different subgroups.

\section{Sensitivity analysis}

The sensitivity analysis was conducted to assess the consistency of the above results and performed by sequential omission of each individual study by using the "metaninf" STATA command. There was no significant change in the pooled HRs suggesting that our results were robust (data not shown).

\section{Publication bias}

We conducted a publication bias evaluation for the studies in terms of OS and DFS (Fig. $4 \mathrm{~A}$ and 4B). The Begg's funnel plot, which provides a visual assessment of the included studies and identifies any overt publication bias, was found to be symmetrical. An Egger's test, which was applied for the formal evaluation of the studies, confirmed the absence of any significant publication bias $(\mathrm{P}>0.1)$.

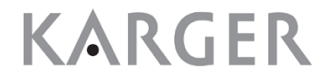




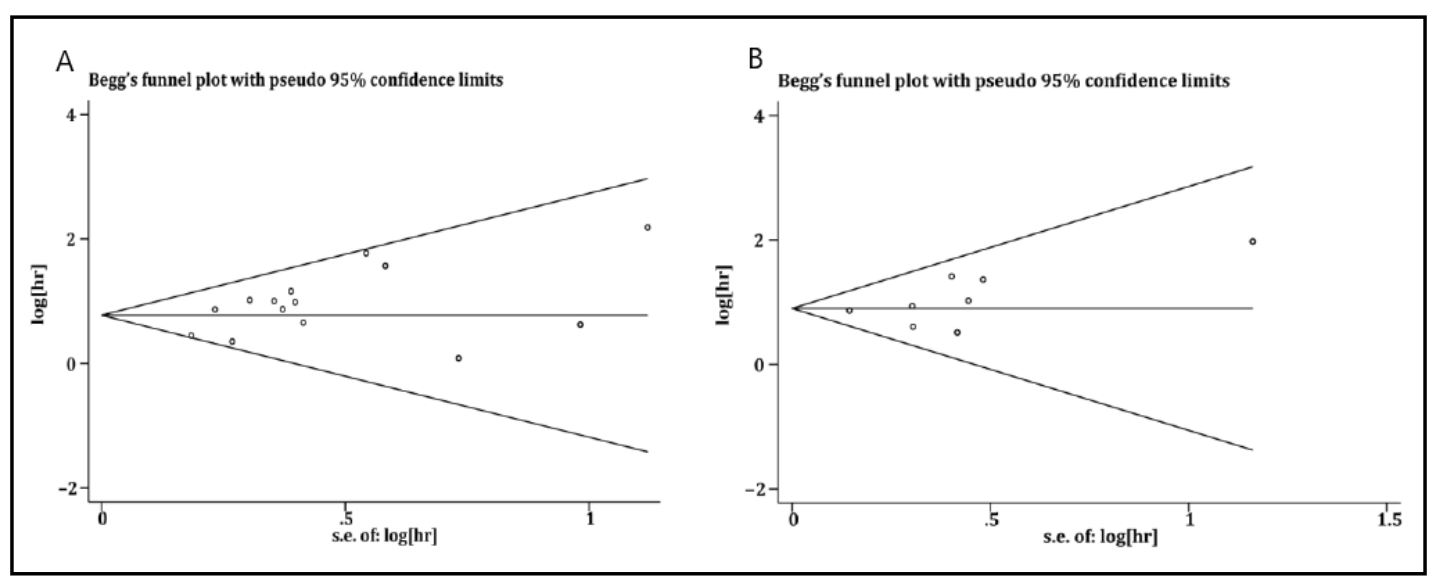

Fig. 4. Funnel plots of publication bias regarding the relationships between high Stathmin 1 expression and (A) OS and (B) DFS, inpatients with solid cancer types.

\section{Discussion}

Stathmin 1 is a microtubule-regulating protein that has an important role in the assembly and disassembly of the mitotic spindle [37]. At the molecular level, Stathmin 1 depolymerizes microtubules by either sequestering free tubulin dimers or directly inducing microtubule-catastrophe [31]. As mentioned before, Stathmin 1 is encoded by the human STMN1 gene, which has 4 serine phosphorylation sites. Phosphorylation at either Ser16 or Ser63 strongly reduces or abolishes the ability of STMN1 to bind to and sequester soluble tubulin [38]. STMN1 Ser16 can be phosphorylated by protein kinase C (PKC), PAK1, or $\mathrm{Ca}^{2+} /$ calmodulin-dependent kinase II/IV $[39,40]$, whereas Ser25 and Ser38 are targeted by mitogen-activated protein kinases (MAPKs) and cyclin-dependent kinases (CDKs) [41]. Overexpression of STMN1 in human cancer not only disrupts normal cell-cycle progression but, more importantly, facilitates polyploidy/aneuploidy of the targeted cells [15]. Stathmin 1 has been implicated in both G1-S and G2-M checkpoint control of cell-cycle progression by influencing the dynamics of microtubule formation and progression of the cell cycle [30]. Kang et al. [42] found that aberrant p53 immunoreactivity was associated with higher STMN1 expression in gastric adenocarcinoma, suggesting that overexpression of STMN1 might be partially due to inactivation of tumor-suppressor gene p53. Batsaikhan et al. [29] also demonstrated that activation-induced cytidine deaminase (AID) could be one of the activators of Stathmin 1 protein expression in gastric adenocarcinoma. P27 and STMN1 correlation was related either directly or by some other pathway. Matsumoto et al. [43] reported that aberrant AID reduces the copy number of CDKs inhibitors such as CDKN2A and CDKN2B, which are tumor suppressive genes and negatively controlled CDKs. AID could be an activator of the STMN1 protein via the AID/CDKN2A/CDKs/STMN1 pathway.

Recently, it was reported that high expression of Stathmin 1 was associated with poor tumor differentiation, large tumor size, advanced N stage, TNM clinical classification, tumor invasion, and distant metastasis in various human malignancies. In addition, it also demonstrated that inhibition of STMN1 expression can enhance the sensitivity of antimicrotubule chemotherapy drugs. Paclitaxel and vinblastine are the most effective chemotherapeutic agents against various cancers. Paclitaxel is a common cytotoxic agent that accelerates microtubule assembly from tubulin and blocks microtubule depolymerization, which leads to cell mitosis stagnation in the G2/M phase, and ultimately apoptosis. Vinblastine affects micro-tubule protein polymerization and stops mitosis. Although the two mechanisms of drug action are different, they both affect the dynamic balance of microtubules. Alli et al. [9] reported that overexpression of Stathmin 1 has been shown to decrease polymerization 


\section{Cellular Physiology Cell Physiol Biochem 2018;50:66-78 \begin{tabular}{ll|l} 
DOI: 10.1159/000493958 & and Biochemistry & $\begin{array}{l}\text { O 2018 The Author(s). Published by S. Karger AG, Basel } \\
\text { www.karger.com/cpb }\end{array}$
\end{tabular} \\ Mao et al.: High Stathmin 1 Expression in Solid Tumors}

of microtubules and markedly decrease the binding of, and sensitivity to, paclitaxel, but not affect the sensitivity to chemotherapeutic drugs that do not target microtubules in human breast cancer. Harada et al. [11] also demonstrated that high expression of Stathmin 1 might have poor therapeutic effects in OSCC treated with docetaxel-containing regimens. Meanwhile, a previous study reported that there was an increased STMN1 expression in the resistant A549 cell line [44], and the expression level of STMN1 was negatively correlated with the efficacy of vinorelbine plus cisplatin/carboplatin therapy in late NSCLC [45]. In addition, Rosell et al. [46] found that STMN1 levels could influence the time to progression of vinorelbine/cisplatin-treated patients. In addition, similar outcomes are also found in patients who treated with vinblastine [26]. It was speculated that STMN1 is critical in the anti-paclitaxel mechanism that blocks microtubule polymerization and reduces its binding to paclitaxel. It was also reported that the transcription factor forkhead box protein M1 (FOXM1) mediates resistance to docetaxel in gastric cancer via up-regulating Stathmin 1 [47]. Moreover, Stathmin 1 has stronger potential as a therapeutic target [10].

Our study provides a systematic analysis of the role of Stathmin 1 expression as a prognostic factor for solid tumors. We identified that high Stathmin 1 expression was associated with shorter OS, DFS, DSS and PFS/RFS, regardless of tumor type, ethnicity, method used to calculate HRs, detected method, and analysis type, except for HRs estimated indirectly by data extrapolated $(\mathrm{P}=0.083)$, as well as analysis type not reported $(\mathrm{P}=0.083)$. Actually, these were the same 2 studies analyzed in different subgroups. Considering the lower sample size of the only subgroup with different results (140 patients), we can ignore this inconsistent result to some extent.

However, this meta-analysis has several limitations. First, although 23 articles from 26 studies were included in this meta-analysis, the sample size (5335 patients) was relatively small. Second, we only considered studies that calculated, or allowed for the calculation of, HRs and 95\% CIs. Other studies that provided odds ratios and relative risk estimates for survival were excluded. In addition, several HRs were calculated based on data extracted from the survival curve, bringing minor deviations. Third, due to the lack of a unified cutoff value in Stathmin 1 expression, different cut-off values were used in those studies. The inaccurate cut-off values may affect the availability of Stathmin 1 as a predictive biomarker in cancer prognosis. In view of this situation, a unified measuring method and cut-off value needs to be established. Fourth, although meta-analysis is now a widely used technique for summarizing evidence from multiple studies, it has its own limitations. All meta-analyses are affected by the quality of the included studies, and by the possibility of publication bias. Finally, owing to the lack of sufficient data, we could not explore the association between Stathmin 1 and other clinical parameters.

\section{Conclusion}

This meta-analysis demonstrated that high Stathmin 1 expression is associated with poor prognosis among study patients with solid tumors. Stathmin 1could be used to substantially improve prognosis estimation and treatment decision-making. However, due to the limitation of the present analysis, this conclusion should be regarded cautiously. There is a need for further studies designed adequately with multicenter and larger sample size study designs to confirm our findings, as well as to explore more effective therapeutic strategies.

\section{Disclosure Statement}

The authors declare that no conflicts of interest exist. 


\section{Cellular Physiology Cell Physiol Biochem 2018;50:66-78 \begin{tabular}{ll|l} 
and BiOChemistry & $\begin{array}{l}\text { DOI: 10.1159/000493958 } \\
\text { Published online: 3 October } 2018\end{array}$ & $\begin{array}{l}\text { (c) } 2018 \text { The Author(s). Published by S. Karger AG, Basel } \\
\text { www.karger.com/cpb }\end{array}$ \\
\hline
\end{tabular}}

Mao et al.: High Stathmin 1 Expression in Solid Tumors

\section{References}

1 Torre LA, Bray F, Siegel RL, Ferlay J, Lortet-Tieulent J, Jemal A: Global cancer statistics, 2012. CA Cancer J Clin 2015;65:87-108.

-2 Olver I: Cancer control-A global perspective. Eur J Cancer Care (Engl) 2017; DOI:10.1111/ecc.12654.

$>3$ Rana S, Maples PB, Senzer N, Nemunaitis J: Stathmin 1: a novel therapeutic target for anticancer activity. Expert Rev Anticancer Ther 2008;8:1461-1470.

4 Ferrari AC, Seuanez HN, Hanash SM, Atweh GF: A gene that encodes for a leukemia-associated phosphoprotein (p18) maps to chromosome bands 1p35-36.1. Genes Chromosomes Cancer 1990;2:125129.

-5 Charbaut E, Curmi PA, Ozon S, Lachkar S, Redeker V, Sobel A: Stathmin family proteins display specific molecular and tubulin binding properties. J Biol Chem 2001;276:16146-16154.

-6 Cassimeris L: The oncoprotein 18/stathmin family of microtubule destabilizers. Curr Opin Cell Biol 2002;14:18-24.

7 Rubin CI, Atweh GF: The role of stathmin in the regulation of the cell cycle. J Cell Biochem 2004;93:242250.

8 Belletti B, Baldassarre G: Stathmin: a protein with many tasks. New biomarker and potential target in cancer. Expert Opin Ther Targets 2011;15:1249-1266.

-9 Alli E, Bash-Babula J, Yang JM, Hait WN: Effect of stathmin on the sensitivity to antimicrotubule drugs in human breast cancer. Cancer Res 2002;62:6864-6869.

10 Hemdan T, Linden M, Lind SB, Namuduri AV, Sjostedt E, de Stahl TD, Asplund A, Malmstrom PU, Segersten $\mathrm{U}$ : The prognostic value and therapeutic target role of stathmin-1 in urinary bladder cancer. Br J Cancer 2014;111:1180-1187.

11 Harada K, Ferdous T, Harada T, Ueyama Y: High expression of stathmin 1 is a strong prognostic marker in oral squamous cell carcinoma patients treated by docetaxel-containing regimens. Clin Exp Med 2017;17:45-50.

12 Su D, Smith SM, Preti M, Schwartz P, Rutherford TJ, Menato G, Danese S, Ma S, Yu H, Katsaros D: Stathmin and tubulin expression and survival of ovarian cancer patients receiving platinum treatment with and without paclitaxel. Cancer 2009;115:2453-2463.

13 Nie W, Xu MD, Gan L, Huang H, Xiu Q Li B: Overexpression of stathmin 1 is a poor prognostic biomarker in non-small cell lung cancer. Lab Invest 2015;95:56-64.

-14 Cheng AL, Huang WG, Chen ZC, Peng F, Zhang PF, Li MY, Li F, Li JL, Li C, Yi H, Yi B, Xiao ZQ: Identification of novel nasopharyngeal carcinoma biomarkers by laser capture microdissection and proteomic analysis. Clin Cancer Res 2008;14:435-445.

15 Hsieh SY, Huang SF, Yu MC, Yeh TS, Chen TC, Lin YJ, Chang CJ, Sung CM, Lee YL, Hsu CY: Stathmin1 overexpression associated with polyploidy, tumor-cell invasion, early recurrence, and poor prognosis in human hepatoma. Mol Carcinog 2010;49:476-487.

16 Akhtar J, Wang Z, Jiang WP, Bi MM, Zhang ZP: Stathmin overexpression identifies high risk for lymphatic metastatic recurrence in pN0 esophageal squamous cell carcinoma patients. J Gastroenterol Hepatol 2014;29:944-950.

17 Zheng P, Liu YX, Chen L, Liu XH, Xiao ZQ, Zhao L, Li GQ, Zhou J, Ding YQ, Li JM: Stathmin, a new target of PRL-3 identified by proteomic methods, plays a key role in progression and metastasis of colorectal cancer. J Proteome Res 2010;9:4897-4905.

18 Kuang XY, Chen L, Zhang ZJ, Liu YR, Zheng YZ, Ling H, Qiao F, Li S, Hu X, Shao ZM: Stathmin and phosphostathmin protein signature is associated with survival outcomes of breast cancer patients. Oncotarget 2015;6:22227-22238.

19 Moher D, Liberati A, Tetzlaff J, Altman DG, Group P: Preferred reporting items for systematic reviews and meta-analyses: the PRISMA statement. Int J Surg 2010;8:336-341.

20 Stang A: Critical evaluation of the Newcastle-Ottawa scale for the assessment of the quality of nonrandomized studies in meta-analyses. Eur J Epidemiol 2010;25:603-605.

21 Parmar MK, Torri V, Stewart L: Extracting summary statistics to perform meta-analyses of the published literature for survival endpoints. Stat Med 1998;17:2815-2834.

22 Tierney JF, Stewart LA, Ghersi D, Burdett S, Sydes MR: Practical methods for incorporating summary timeto-event data into meta-analysis. Trials 2007;8:16. 


\section{Cellular Physiology Cell Physiol Biochem 2018;50:66-78 \begin{tabular}{ll|l} 
and Biochemistry Published onlIne: 3 October 2018 & $\begin{array}{l}\text { (c) } 2018 \text { The Author(s). Published by S. Karger AG, Basel } \\
\text { www.karger.com/cpb }\end{array}$
\end{tabular}}

Mao et al.: High Stathmin 1 Expression in Solid Tumors

23 Ma HL, Jin SF, Tao WJ, Zhang ML, Zhang ZY: Overexpression of stathmin/oncoprotein 18 correlates with poorer prognosis and interacts with p53 in oral squamous cell carcinoma. J Craniomaxillofac Surg 2016;44:1725-1732.

24 Kouzu Y, Uzawa K, Koike H, Saito K, Nakashima D, Higo M, Endo Y, Kasamatsu A, Shiiba M, Bukawa H, Yokoe $\mathrm{H}$, Tanzawa H: Overexpression of stathmin in oral squamous-cell carcinoma: correlation with tumour progression and poor prognosis. Br J Cancer 2006;94:717-723.

25 Wei SH, Lin F, Wang X, Gao P, Zhang HZ: Prognostic significance of stathmin expression in correlation with metastasis and clinicopathological characteristics in human ovarian carcinoma. Acta Histochem 2008;110:59-65.

-26 Wang H, Li W, Wang G, Zhang S, Bie L: Overexpression of STMN1 is associated with the prognosis of meningioma patients. Neurosci Lett 2017;654:1-5.

27 Liu H, Li Y, Li Y, Zhou L, Bie L: STMN1 as a candidate gene associated with atypical meningioma progression. Clin Neurol Neurosurg 2017;159:107-110.

-28 Neben K, Korshunov A, Benner A, Wrobel G, Hahn M, Kokocinski F, Golanov A, Joos S, Lichter P: Microarraybased screening for molecular markers in medulloblastoma revealed STK15 as independent predictor for survival. Cancer Res 2004;64:3103-3111.

-29 Batsaikhan BE, Yoshikawa K, Kurita N, Iwata T, Takasu C, Kashihara H, Shimada M: Expression of Stathmin1 in gastric adenocarcinoma. Anticancer Res 2014;34:4217-4221.

-30 Akhtar J, Wang Z, Yu C, Zhang ZP, Bi MM: STMN-1 gene: a predictor of survival in stage iia esophageal squamous cell carcinoma after Ivor-Lewis esophagectomy? Ann Surg Oncol 2014;21:315-321.

31 Wang F, Xuan XY, Yang X, Cao L, Pang LN, Zhou R, Fan QX, Wang LX: Stathmin is a marker of progression and poor prognosis in esophageal carcinoma. Asian Pac J Cancer Prev 2014;15:3613-3618.

-32 Reyes HD, Miecznikowski J, Gonzalez-Bosquet J, Devor EJ, Zhang Y, Thiel KW, Samuelson MI, McDonald M, Stephan JM, Hanjani P, Guntupalli S, Tewari KS, Backes F, Ramirez N, Fleming GF, Filiaci V, Birrer MJ, Leslie KK: High stathmin expression is a marker for poor clinical outcome in endometrial cancer: An NRG oncology group/gynecologic oncology group study. Gynecol Oncol 2017;146:247-253.

-33 Trovik J, Wik E, Stefansson IM, Marcickiewicz J, Tingulstad S, Staff AC, Njolstad TS, Vandenput I, Amant F, Akslen LA, Salvesen HB: Stathmin overexpression identifies high-risk patients and lymph node metastasis in endometrial cancer. Clin Cancer Res 2011;17:3368-3377.

34 Zhang HQ Guo X, Guo SQ, Wang Q Chen XQ, Li XN, Guo LS: STMN1 in colon cancer: expression and prognosis in Chinese patients. Eur Rev Med Pharmacol Sci 2016;20:2038-2044.

-35 Baquero MT, Hanna JA, Neumeister V, Cheng H, Molinaro AM, Harris LN, Rimm DL: Stathmin expression and its relationship to microtubule-associated protein tau and outcome in breast cancer. Cancer 2012;118:4660-4669.

-36 Golouh R, Cufer T, Sadikov A, Nussdorfer P, Usher PA, Brunner N, Schmitt M, Lesche R, Maier S, Timmermans M, Foekens JA, Martens JW: The prognostic value of Stathmin-1, S100A2, and SYK proteins in ER-positive primary breast cancer patients treated with adjuvant tamoxifen monotherapy: an immunohistochemical study. Breast Cancer Res Treat 2008;110:317-326.

-37 Wang R, Dong K, Lin F, Wang X, Gao P, Wei SH, Cheng SY, Zhang HZ: Inhibiting proliferation and enhancing chemosensitivity to taxanes in osteosarcoma cells by RNA interference-mediated downregulation of stathmin expression. Mol Med 2007;13:567-575.

38 Manna T, Thrower DA, Honnappa S, Steinmetz MO, Wilson L: Regulation of microtubule dynamic instability in vitro by differentially phosphorylated stathmin. J Biol Chem 2009;284:15640-15649.

-39 Chen PW, Lin SJ, Tsai SC, Lin JH, Chen MR, Wang JT, Lee CP, Tsai CH: Regulation of microtubule dynamics through phosphorylation on stathmin by Epstein-Barr virus kinase BGLF4. J Biol Chem 2010;285:1005310063.

40 Wittmann T, Bokoch GM, Waterman-Storer CM: Regulation of microtubule destabilizing activity of Op18/ stathmin downstream of Rac1. J Biol Chem 2004;279:6196-6203.

41 Hayashi K, Pan Y, Shu H, Ohshima T, Kansy JW, White CL, 3rd, Tamminga CA, Sobel A, Curmi PA, Mikoshiba $\mathrm{K}$, Bibb JA: Phosphorylation of the tubulin-binding protein, stathmin, by Cdk5 and MAP kinases in the brain. J Neurochem 2006;99:237-250.

-42 Kang W, Tong JH, Chan AW, Lung RW, Chau SL, Wong QW, Wong N, Yu J, Cheng AS, To KF: Stathmin1 plays oncogenic role and is a target of microRNA-223 in gastric cancer. PLoS One 2012;7:e33919. 


\section{Cellular Physiology Cell Physiol Biochem 2018;50:66-78 \begin{tabular}{l|l|l} 
DOI: 10.1159/000493958 & $\begin{array}{l}\text { O } 2018 \text { The Author(s). Published by S. Karger AG, Basel } \\
\text { www.karger.com/cpb }\end{array}$ \\
\hline
\end{tabular} \\ Mao et al.: High Stathmin 1 Expression in Solid Tumors}

43 Matsumoto Y, Marusawa H, Kinoshita K, Niwa Y, Sakai Y, Chiba T: Up-regulation of activation-induced cytidine deaminase causes genetic aberrations at the CDKN2b-CDKN2a in gastric cancer. Gastroenterology 2010;139:1984-1994.

44 Martello LA, Verdier-Pinard P, Shen HJ, He L, Torres K, Orr GA, Horwitz SB: Elevated levels of microtubule destabilizing factors in a Taxol-resistant/dependent A549 cell line with an alpha-tubulin mutation. Cancer Res 2003;63:1207-1213.

45 Pu X, Wang J, Xu L, Ma J, Wang Z, Liu F, Yang M, Fan W, Meng L: [Relationship between Expression of beta-tubulin-III Plus Stathmin in Advanced Non-Small Cell Lung Cancer and its Sensitivity to Venorelbine Chemotherapy.]. Zhongguo Fei Ai Za Zhi 2009;12:49-53.

\$6 Rosell R, Scagliotti G, Danenberg KD, Lord RV, Bepler G, Novello S, Cooc J, Crino L, Sanchez JJ, Taron M, Boni C, De Marinis F, Tonato M, Marangolo M, Gozzelino F, Di Costanzo F, Rinaldi M, Salonga D, Stephens C: Transcripts in pretreatment biopsies from a three-arm randomized trial in metastatic non-small-cell lung cancer. Oncogene 2003;22:3548-3553.

47 Li X, Yao R, Yue L, Qiu W, Qi W, Liu S, Yao Y, Liang J: FOXM1 mediates resistance to docetaxel in gastric cancer via up-regulating Stathmin. J Cell Mol Med 2014;18:811-823. 